\title{
The Effects of Age at Prison Release on Women's Desistance Trajectories: a Mixed-Method Analysis
}

\author{
Erin M. Kerrison ${ }^{1}$ • Ronet Bachman ${ }^{2}$ • \\ Raymond Paternoster ${ }^{3}$
}

Received: 27 January 2016 / Revised: 24 June 2016 / Accepted: 11 August 2016 /

Published online: 8 September 2016

(C) Springer International Publishing AG 2016

\begin{abstract}
Purpose The purpose of this study is to measure the effect that age has on women's gendered prisoner reentry experiences and the likelihood of desisting from crime and substance abuse. This study also seeks to evaluate the applicability of Paternoster and Bushway's (2009) Identity Theory of Desistance (ITD) for a contemporary, all-female sample.

Methods This mixed-method study makes use of official arrest data for 218 women leaving Delaware prisons in the mid 1990s, to create group-based offending trajectory models. A representative subsample of 118 women was interviewed between 2009 and 2011 and asked to conceptualize the mechanisms that led to their desistance or persistence in offending.

Results Multinomial logistic regression analyses reveal that for some of the sample, age at the time of release from prison has a positive effect on the likelihood that women will belong to a desisting trajectory group rather than the most deviant reference group. Interview narratives demonstrate that in navigating the post-incarceration gendered experiences of securing employment, family reunification, and substance abuse recovery, maturity, clarity about one's personal responsibility for linked failures, and a desire to transform one's identity were significant factors that preceded the capacity to excel in those reentry domains.

Conclusions These findings lend support for the applicability of ITD for women's desistance experiences. As older women appear to express a reentry goal orientation that diverges from that of their younger counterparts, gender-responsive rehabilitation
\end{abstract}

Erin M. Kerrison

kerrison@berkeley.edu

1 School of Social Welfare, University of California, Berkeley, Berkeley, CA 94720, USA

2 Department of Sociology and Criminal Justice, University of Delaware, Newark, DE 19716, USA

3 Department of Criminology and Criminal Justice, University of Maryland, College Park, College Park, MD 20742, USA 
agendas must also include programming that increases the likelihood that participants will connect failures sooner so that the prosocial benefits of a healthy identity change can be enjoyed for longer.

Keywords Age · Desistance $\cdot$ Gendered pathways · Identity theory · Women

\section{Introduction}

There are many theoretical explanations for the age-crime curve and the fairly consistent point at which offending patterns drastically diminish for the majority of offending adults. Explanatory emphases have been placed on the supervisory impact felt upon entry into prosocial institutions and adult social bonds [69, 103], the short durational prevalence of normative anti-social adolescent behavior [80], and evidence that the precipitous declines in offending following adolescence are attributed to rational responses to changes in the perceived costs and benefits of crime [92]. Although an interdisciplinary research focus on the age-crime curve has developed in very meaningful ways, most of the inquiry has explored men's offending patterns or mixedgender samples of adolescents and younger adults. Further, of those studies that do explore the desistance experiences of women, less is known about the contemporary, gendered reentry process navigated by an increasingly female, serious, drug-involved cohort. In the present study, we examine how women's age upon release from prison is related to their desistance efforts and we explicitly link our analysis to Paternoster and Bushway's [93] affirmations of the Identity Theory of Desistance.

Age-graded informal social control [69], cognitive transformational theory [43, 44], and the Identity Theory of Desistance [91, 93] in varying degrees all take on the significance of employment, romantic partnerships, parenting, and agency in the desistance process. The sample of men upon which much of Sampson and Laub's age-graded informal social control theory was based featured a cohort of young White males who came of age in the 1950s and were able to change their criminal behavior via prosocial routes such as securing gainful manufacturing employment positions and enjoying the benefits of a committed, conformist spouse. Maruna and colleagues [38, 73-75] highlighted the psychological mechanisms that appear to explain desistance successes for more contemporary male samples. They theorize that desistance involves individuals reinterpreting their past criminal identities with prosocial views of themselves to reconcile their current identities as good people. This work was expanded by research by Giordano and her colleagues $[43,44]$ who collected data from a prospective cohort of adolescent offenders transitioning to early adulthood. They contended that "cognitive transformations" within individuals must first occur before they would be open to prosocial opportunities or "hooks for change," such as employment and healthy partnerships.

Paternoster and Bushway ([93]; [25, 26]) offer one of the most recent theoretical formulations explaining desistance, the Identity Theory of Desistance (ITD). Persons who commit crimes, Paternoster and Bushway [93] contended, will retain an offender working identity as long as they perceive that it will net more benefits than costs. The process of changing an offender identity is gradual and occurs with the crystallization of discontent or "when perceived failures and dissatisfactions within different domains 
of life become connected, and when current failures become linked with anticipated future failures" ([93], p. 1105). When offenders realize that their criminal involvement is either currently more costly than beneficial and/or is projected to be more costly in the future, they make initial moves to change their identity away from a track that is headed toward that future "feared self" and toward one that is marked by behaviors and peer networks that will stabilize the emerging, sustainably law-abiding self. This newly emerging prosocial "possible" identity triggers a diminished preference for things like quick and easy money and instead motivates an intention to identify and create a conventional social network that is consistent with the new persona. It is this internal change in identity and the recognition of the kind of person that one wants to be that both motivates behavior consistent with a prosocial identity (e.g., change in preferences, desire for legitimate work, seeking conventional friends) and sends a signal to others (like potential prosocial intimates and employers) that the person is making positive changes in their life.

The important time order articulated by the ITD, then, is an initial change in a former offender's identity that both explains the subsequent movement into conventional roles and explains why those who had previously been involved in crime would ever be receptive to these prosocial influences. In other words, the identity change in Paternoster and Bushway's theory provides an explanation as to why an offender's behavior framed within the theoretical context of Giordano et al.'s theory would be open to change and more receptive to prosocial influences and also explains the arrival of prosocial turning points in the Sampson and Laub's age-graded informal social control. Furthermore, while conventional turning points are extremely useful in desisting, they are not essential as one with a changed identity can, though not without some difficulty, cobble together a life that does not involve criminal behavior, even if their life does not include a good job or good partnership. Emotionally satisfying intimate relationships and stable employment are not essential for desistance, but a structural "break with the past" ([93], p. 1107) or an intentional shift in one's sense of self is. It is this gradual change in identity that is the willful purposive act of committing to self-improvement that leads, in turn, to other prosocial changes. Absent a commitment to identity change, the influence of external prosocial institutions will not endure.

Although the theoretical assumptions of ITD do not explicitly include a treatment of how age and gender structure identity and identity change, we believe that both are salient in the construction of the desistance process. With respect to the influence of gender constructions, ITD looks at the timing and variability of structural breaks, which are potentially linked to milestones that emerge throughout our gendered lives (onset of sexual activity, labor market entry, parenthood, etc.). With regard to the impact of age on the structure of identity formation and the potential for change, we believe that beyond the biological significance of aging and the physical burdens that complicate criminal opportunities, older adults are more likely to see the real and present danger of an undesirable future self. In other words, there are many younger adults who are criminally involved and whose health suffers at the expense of ongoing substance abuse, however, they may believe that there is still ample time to turn their lives around. We believe that a gradual accumulation and connection of diverse negative events tends to occur for older adults and will explore the extent to which these developments impact desistance for criminally involved women who may feel as though they have less time to squander. 
While the empirical evidence regarding the impact that marriage and employment have on women's desistance remains equivocal, recent empirical work exploring the experiences of female offenders has illuminated the importance of identity in the desistance process. Opsal [90] examined the role of both employment and identity in desistance from crime within an interviewed sample of 43 female ex-offenders, with the interviews taken both immediately after the women were released from incarceration and again approximately 3 months later. To summarize the results, Opsal found that both conventional employment and identity change were important in the desistance process, though it was impossible to make a clean causal inference as to whether identity change or jobs came first. There was clear evidence from the narratives, however, that the process of desistance involved the ideas of a feared and possible self that are central to the identity theory. One of Opsal's study participants ([90]: 388) reflects this: "So, I got another chance and I'm gonna do it this time, because I want to change. I want to go home and be with my kids. I want to live a drug-free life. I want to be able to be an abiding citizen and do what I need to do and not always be in trouble and be bad-ass. That is not me." The female former offenders in Opsal's sample illustrate the difficulties that serious offenders have upon reentry. All were unable to find the kinds of stable, well-paying jobs that formerly incarcerated men returning to a mid-20th-century industrial labor market could secure. Instead, when these women found jobs, they were generally in the food service and janitorial sector, netting a minimum wage income absent health insurance benefits or long-term security.

Breen [20] conducted a mixed-methods study of 27 pregnant and parenting women with extensive criminal records and reported results consistent with ITD. First, many of the women initiated desistance when they became dissatisfied with their life of crime. Particularly important to some was the construction of the feared self with respect to their children. For example, one woman indicated that she had constructed a prosocial positive self and a roadmap to get to a place where she would not have to deliver her child while in prison: "... now I realized I have to finish my schooling, I have to get a job." Breen [20] also reported that these desisting women in her sample changed their preferences as well as their identities and adopted more prosocial values. Similar research was conducted by Sharpe [109], who interviewed 19 mothers, each with nontrivial offending histories. These women revealed how difficult it was for serious offenders to secure well-paying jobs and they vividly expressed the stigma that they perceived while attempting to turn their lives around. For many of these women, it was the expectation of the feared self - a failed mother whose children were taken from her by the state - that started them down the path of desistance.

Contemporary female offenders who are juggling the mark of a criminal record, the responsibilities of single parenthood, and extensive substance use disorders that are linked to histories of trauma and abuse must navigate a desistance effort that also is gendered in nature [14, 29, 100]. For example, the supervisory effects of employment may not be known to women who are niched into temporary, transitional, and "under the table pay" part-time positions. Greenfeld and Snell [48] reported that roughly $37 \%$ of female inmates compared to $28 \%$ of incarcerated men reported earning less than $\$ 600$ per month prior to their arrest. More recent data collected by Wright et al. [128] reveal that for a sample of 581 Minnesota women in prison, on probation, and in a drug court program, nearly $50 \%$ were unemployed (with women in prison reporting employment at time of arrest), and more than the majority of that sample reported 
annual incomes of $\$ 10,000$ or less. Economic insecurity is a criminogenic constant in the lives of women with conviction records [55, 83]. Clearly, we must consider how desistance theoretical frameworks that are hinged on the influence of life course events and social processes imbued with gendered significance, shape desistance, and persistence for women in ways that may diverge from the processes experienced by men.

Not only are the processes that shape the age-crime curve necessarily gendered, but they are rather consistently timed where processes and their significance unfold at regularly anticipated intervals $[28,76]$. In other words, the timing of a given life course event suggests that an event's salience is linked to a given subject's age and that age effects matter a great deal [39]. Common themes linked to the catalyst and maintenance of varied desistance efforts include the transitioning from deviant to more conformist social networks, acknowledging the deterrent elements of certain punishment, and even reconciling aging and health complications that preclude a continued deviant lifestyle. Even many of the most criminally enmeshed offenders are still reasoning people governed by acute risk perceptions [6, 79]. Longitudinal studies of offender risk assessment demonstrate that the probability for desistance increases as expectations of rewards and benefits associated with criminal behavior decrease, and the saturation of those positive changes is strongly correlated with age [110, 111]. According to the ITD, offenders are more likely to seek to desist from crime when failures in one's life are linked together and projected into the future, and when the feared self, the self that the offender does not want to become in the future becomes more salient. The salience of the feared self is linked to the age at release since the period of time that one would have to change their life around and desist is shorter when the older one is released. The crucial factor with age at release as it relates to desistance, then, is the time period that one perceives that he or she has to avoid the feared self and become the possible prosocial self.

As study findings illustrate offenders' desire to rewrite what was thought to be fate, and instead create a new nonoffender identity [9, 10, 73], this study explores the applicability of the ITD for a cohort of aging drug-involved female offenders.

\section{Review of Empirical Literature on Age and Women's Desistance}

The vast majority of research explaining desistance from crime and substance abuse, or the process by which individuals quit offending behaviors, has focused exclusively on the experience of male offenders. Some researchers have made inroads into the phenomenon of women's desistance as well as shed some light on the risk factors that begin to explain persistent offending patterns among female samples $[9,10,21,32,51,52$, 118]. For example, Cauffman et al. [28] compared self-reported offending trajectories for nearly 200 serious female offenders to a matched sample of male offenders and found that among persisters represented in the dataset, women were more likely to have been exposed to violence, trauma, and unhealthy interpersonal relationships. Their analyses made use of data from the Pathways to Desistance study [85, 107], which focused on juvenile delinquency and captured the experiences of men and women up to 25 years old. Criminologists must continue to examine the host of risk factors that precipitate persistent offending, as well as the underlying mechanisms of desistance that women are shaped by well after early adulthood. Empirical life course criminological 
studies that do focus on the experiences of contemporary American female offenders largely identify the significance of employment, motherhood, romantic partnerships, substance abuse, and trauma histories in the arc of women's offending patterns. Next, we provide a review of related study findings that include a treatment of age.

For a lasting desistance effort, social scientists have long cited the importance of securing employment. The influence of age on employment outcomes has received less attention, however. Exceptions include Sampson and Laub's [105] findings, which support the theory that working in the military netted otherwise stigmatized male offenders an opportunity to achieve job stability and economic well-being, particularly if they enlisted between the ages of 17 and 25 years old. Uggen [116] also found that among 3000 drug and criminally involved men hailing from the economic underclass of several American cities in the mid-1970s, offender age interacted with employment to negatively affect the rate of self-reported recidivism. For scholars and practitioners looking to increase the likelihood of positive adult employment experiences for developmentally challenged children and teens, Moffitt et al. [80] underscored the importance of early intervention for children and adolescents who exhibit aggressive, impulsive, and anti-social personality traits. These study findings, however, may not be generalizable nor do they necessarily speak to the experiences and prospects of contemporary, mature female offenders. Contemporary studies that do measure the effects of employment on women's self-reported offending and official recidivism are mixed and do not offer much insight into the moderating role of age. While some studies have found that employment status reduces women's offending [22, 32, 119], other research suggests that having a job in and of itself does not necessarily lead to offending cessation, largely because a host of other criminogenic social and psychological factors has not yet been addressed [9, 10, 15, 99].

More has been revealed about the experiences of contemporary female offenders who are also mothers or primary caregivers to children $[12,77,78,112]$, and some of these studies have also explored the moderating effect that age imposes upon motherhood and desistance. To begin, it is important to note that nearly two thirds of women serving sentences in state prisons had children before they committed the offense for which they are now serving time [46, 115, 121]. Given that, it is clearly not the structural role of motherhood that inhibits offending behavior, at least not for the crimes for which many mothers are serving sentences. However, as many crimeinvolved adult women were also teenage mothers [29, 113], it may be the case that with age and maturity comes a readiness to adopt a prosocial identity, and reclaiming their role as mother may indeed serve to solidify their desired change [9, 10, 90]. Simultaneously, there are other studies that suggest that for women who acknowledge their motherhood status and wish to elevate its priority in their prosocial lives, being younger and less criminally enmeshed serves to increase the likelihood that motherhood will catalyze these desistance efforts $[45,66]$. The lack of consensus about the these theoretical time order specifications explains why the research on motherhood and desistance, and the role that age plays in that association, is largely equivocal.

Other scholars interested in women's pathways to desistance have devoted a great deal of energy unpacking the significance of marriage and romantic partnerships. Proponents of the "good marriage" effect, or the influences derived from strong bonds to prosocial partners, base their claims on the experiences of White men who matured during the 1950s and were more likely to partner with domesticated women who did 
not further introduce criminal elements into their adult lives [68, 104]. While these findings are important, they do not speak to the experiences of contemporary drugaddicted female offending samples, many of whom are racially minoritized, living in concentrated disadvantage, and partnered with criminally involved men whose physically and psychologically abusive behaviors exacerbate the desistance process $[97,108$, 125]. Research findings regarding the effects of marriage on women's desistance are largely equivocal. Some have found that marriage reduced offending [17, 32, 51], reduced offending for women with a moderate propensity to marry in the first place [65], increased offending for female probationers who lived with a drug-using spouse [34], or were null [45, 61]. For women who were not married but instead partnered, Griffin and Armstrong [49] found that living with a partner decreased nondrug-related offending but increased access to a male-dominated drug market and subsequently led to increases in relapse and drug use. Qualitative study findings suggest that some of the variation seen in the research discussed above may be explained by taking a closer look at the quality of the women's partnerships and marriages [130]. Just as abusive partnerships impede the desistance process for women [30, 98], a supportive partner who is committed to recovery and stability will support women's desistance efforts [71]. Data suggest, however, that absent gender-responsive treatment and programming that address these histories, women of all ages will struggle with developing healthy partnerships that may support their desistance efforts [122].

Regrettably, many criminal justice supervised individuals are suffering from substance use disorders, but the proportions are greater for women [63, 88]. Many female druginvolved offenders describe their pathways to substance abuse using explanatory discourses that Gueta and Chen [50] identify as characterized by victimization or agency: coping with trauma and the need to self-medicate or substance misuse as an agentic means by which they could cultivate pleasure and control, respectively. Desistance from substance abuse, then, requires that these women address the elements in their lives that prompt them to self-medicate or seek out ways to feel in control that are so utterly selfdestructive. Few studies highlight the ways in which women's substance abuse desistance efforts are moderated by age. For example, research has previously shown that desistance from substance abuse appears to follow a desire to transform into someone who no longer seeks to maintain the longstanding patterns of poor choices and harmful outcomes $[9,10]$, but those findings were derived from a mixed-gender sample. White et al. [124] suggest that for a mixed-race sample of men from Pittsburgh, Pennsylvania, heavy drinking during emerging adulthood (18-25 years old) is normative and does not lead to a violent offending trajectory, but heavy drinking after early adulthood could signal prolonged violent offending patterns. Their findings suggest that the point at which one stops abusing alcohol could presage later deviance. In a later study based on the same Pittsburgh sample, White et al. [123] found that hard drug use and dealing (cocaine and heroin, as opposed to heavy drinking) in early adulthood were associated with serious violent offending later in the life course. Unfortunately, findings from the Pittsburgh cohort may not be representative of the experiences of maturing women.

In sum, some research suggests that age may catalyze desistance efforts for younger, less criminally enmeshed offenders. Other studies underscore the ways in which adulthood maturity and a desire to adopt a nonoffender identity that is consistent with life course achievements of offenders' prosocial counterparts are what prompts desistance. In addition to those mixed findings, much of the literature on desistance does not 
at all consider the experiences of contemporary female offending samples. The equivocal nature of these findings signals a need for an analysis that explores the histories of a range of women (with mixed race, age, and offending patterns) all exiting similar correctional experiences and returning to similar community contexts. This study contributes to this understanding by examining the impact of age at prison release on long-term desistance for a contemporary cohort of drug-involved former female prisoners entrenched within the criminal justice system, returning for the most part to home lives and communities marked by concentrated disadvantage. Our hypothesis is that women who were released from prison at an older age are more likely to have desisted from crime than women who were released at a younger age.

\section{Methods}

\section{Sample}

The data for this study are derived from a multi-phase longitudinal analysis of a cohort of serious drug-involved offenders who were released from several state prisons in Delaware between 1990 and 1996. Although some study participants had served prison sentences both prior to, and/or after that 6-year period of data collection, we refer to the first time that they released during those 6 years of observation, as their "baseline" release from custody. The baseline study was designed to examine the effectiveness of a drug rehabilitation program and consisted of 1247 male and female inmates who were randomly assigned to a treatment condition, which was enrollment in the therapeutic community drug program [62]. Subjects in the study were first surveyed while still incarcerated, approximately 9 months prior to release from that baseline incarceration period, and then were resurveyed after being released from that baseline incarceration at $6,18,42$, and 60 months. Survey information was extensive, including basic demographics, criminal and drug use history, substance abuse treatment history, living arrangements, sexual behavior, physical and mental health indicators, and various attitudinal measures. For this study, we will focus on the experiences of the 224 women whose offending patterns were observed.

\section{Quantitative Data Collection}

To determine patterns of desistance within the cohort, arrest and incarceration histories for each subject that covered the years 1989 to 2008 were collected from the Delaware Statistical Analysis Center, which records all adult arrests and imprisonments in the state of Delaware. These data were augmented with arrest records derived from the National Crime Information Center in order to capture arrest and imprisonment activity that occurred outside of the state of Delaware. With these data, we amassed a count of the number of arrests for each person per year. The incarceration data that we collected for each study subject also included entrance and exit dates for each period of custody, which allowed us to compute the number of days that each person was free during the 18-year observation period. In calculating desistance trends for this cohort, these incarceration data allowed us to control for the time that individuals spent under incustody correctional supervision. 
To illuminate the various paths of desistance for the cohort, the first phase of our analysis strategy began with the estimation of a group-based trajectory model for these arrest history data [86]. The offending histories on which these analyses are based included arrest and incarceration histories for 224 women over the nearly 20 -year observation period. The mean number of arrests for women in the sample was 29.9 (for which property offense commission was the modal top charge), they spent an average of 3.6 years incarcerated, and the mean age at the time of their baseline incarceration release was 29.8 years old. Female specific trajectory models were estimated, which resulted in a five-group model (all quadratic) that best fit the data. This female-specific model is displayed in Fig. 1, and demographic details for the subsample are displayed in Table 1. The names provided for each group are purely subjective and based on the average number of arrests that each group accumulated per year (represented on the $y$ axis) after their baseline release. Three of the five groups highlight a desisting pattern where mean arrest rates deescalated to fewer than 0.5 arrests per year by the end of the observation period in 2008. The two remaining offending trajectory groups (groups 1 and 4) evidence a persistent involvement in criminal activity over time and at least a mean of 1.5 arrests per year at the end of 2008. These persisting groups combined represent about $34 \%$ of our female sample. In the quantitative analysis of this paper, multinomial regression models will be estimated predicting the probability of belonging to the high-level persisting group compared to all other groups, with age at baseline release as our primary independent variable of interest.

\section{Qualitative Data Collection}

A stratified random sample of 118 women was selected for intensive face-to-face interviews from each of the five trajectories (for a full discussion of the procedures used to locate respondents and analyze the narratives, see [8]. The purposes of these qualitative interviews were to illuminate the mechanisms for change in offending over time

\section{Arrest Trajectory Group Membership for Females from 1989-2008, $\mathrm{N}=\mathbf{2 1 8}$}

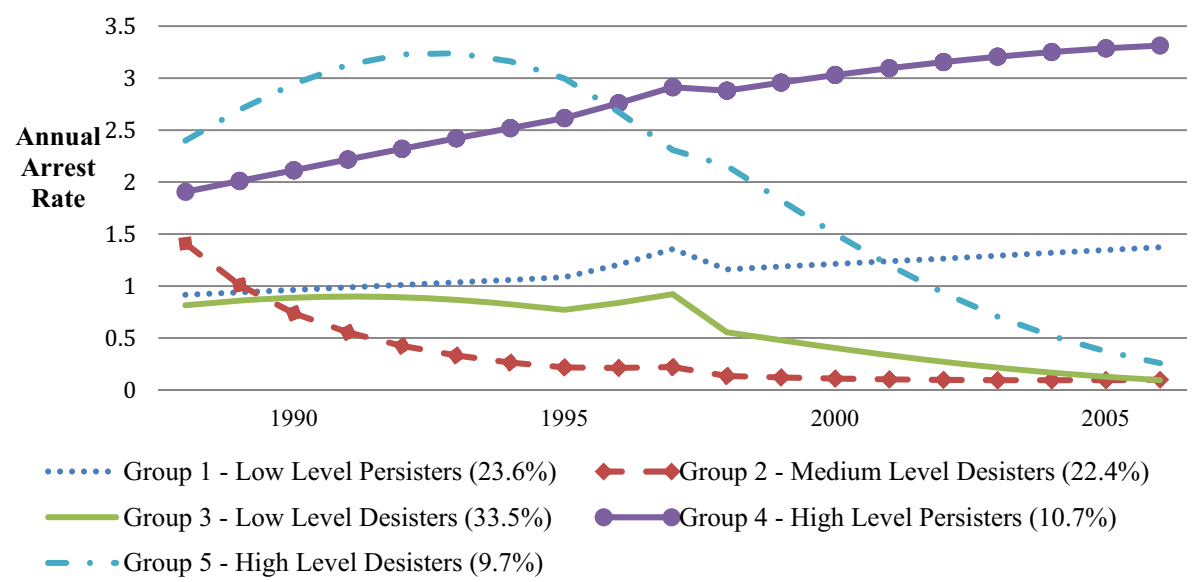

Fig. 1 Arrest trajectory group membership for women from 1989 to 2008 . $N=218$ 
Table 1 Demographic details for interviewed female respondents, $N=105$

Percent

Group 1: low-level persisters

Group 2: medium-level desisters

Group 3: low-level desister

Group 4: high-level persisters

Group 5: high-level desisters

African American

Had children at baseline of original study

Mean age at first adult arrest

Mean age at baseline incarceration release

Mean age at interview

Self-reported offending behavior

Did not use illegal substances or engage in criminal activity after first release from prison (immediate desistance)

Used illegal substances within year of interview

Crack

Marijuana

Heroin

Still addicted to alcohol

Illegal use of prescription drugs

Combination of drugs

$\begin{array}{ll}\text { Engaged in other criminal activity within year of interview } & 24\end{array}$

Violence

Theft/fraud

Violation of parole/probation

and allow respondents to speak directly for themselves about what changes that they felt that they had undergone over the years since their baseline incarceration, including the factors that both facilitated and inhibited offending.

Respondents selected for interviews were first contacted by mail requesting that they call a research office phone number at a local university if they were willing to participate in the interview. Follow-up was needed in many cases and was done first by another letter, then by phone, and finally by personal visits in a few cases. All interviews that took place at the university office site lasted from 1 to $3 \mathrm{~h}$ and were digitally tape-recorded. Respondents were compensated $\$ 100$ for their time and travel expenses. Not surprisingly, sample attrition was an unavoidable problem when attempting to contact study participant years after their last survey. Approximately $11 \%$ of the original sample was deceased, $13 \%$ were still incarcerated, $3 \%$ were found to be living out of state, and $7 \%$ were unreachable by any means. Although we originally did not want to conduct interviews with those still in prison because the Department of Corrections did not allow tape recorders, three women who were in the persisting categories were interviewed while in custody in the effort to increase the 
sample size of those trajectory groups. Detailed field notes were used to analyze the four interviews conducted in correctional settings. Only two women were identified as bi-racial, and all official records indicated that respondents were either White or Black. Of the 118 women interviewed, the majority was Black (73\%), and the mean age was 45 years at the time of the interview. The response rate for those who were successfully contacted and living in Delaware was approximately $96 \%$.

The goal of the interviews was to uncover what Agnew [2] referred to as "storylines" in understanding criminal offending. A storyline is a "temporally limited, interrelated set of events and conditions that increase the likelihood that individuals will engage in crime" (p. 121). The interview guide resembled an event history calendar, which has proven to be an extremely useful tool for collecting retrospective data on life events within different domains such as subjects' relationship changes, medical history, and offending [16]. Another important tool that we used in our interview guide to facilitate respondents' recall was the placement of arrest and incarceration dates obtained from official data within the calendars, as well as key life events such as birthdays, to be used as heuristic cues to aid recall. These cues proved extremely useful for helping respondents recall both their offending histories as well as other life events. Despite the utility of the event history calendar-inspired interview guide, the interviews were primarily open ended and resembled conversations rather than an exchange of formal survey questions and answers. For each criminal and drug relapse event self-reported or obtained from official records, respondents were asked to recreate the event both perceptually and structurally, and interviewers probed for respondents' cognitive decision-making processes surrounding those events.

All interviews were transcribed verbatim and imported into NVivo for coding. The analytical process of coding involved a number sequential stages that identified ideas and themes as opposed to counts of explicit words or phrases [87]. The coding team included this article's first and second authors as well as two graduate research assistants. The coding process began with a list of initial categories derived from the existing desistance literature and included such key indicators as turning points, indicators of agency and readiness for change, and the psychological indicators of discontent and fear. Before coding began, training sessions ensured that definitions of each category were understood and that consensus was reached for a standardized practice of coding procedures. Next all researchers coded the same transcripts and discussed their coding strategies during group meetings. In these team meetings, decisions to add new categories through a grounded theory approach [31] were adjudicated and coding discrepancies were discussed and resolved. This team dynamic, we believe, allowed the emotional expression of the researchers to enhance the conceptual decision-making process [106].

The coding process continued with eight weekly reliability meetings in which a new interview was coded by all four researchers. To facilitate future analyses, all emergent themes were coded, which resulted in more than 20 main categories (e.g., discontent, turning points, incarceration) and more than 100 subcategories used in the coding scheme. This coding strategy allowed a breadth of coding domains to be created that were not mutually exclusive but would be invaluable to future research using these data, even though fewer codes may have allowed us to more easily provide global tallies of emergent themes. Discrepancies in coding did not come from a lack of correspondence with key domains but from the fact that some coders may have 
simultaneously placed a narrative into several domains, whereas another coder may have placed it within only one domain. For example, one coder may have placed the mention of childhood abuse by a mother in several domains, such as "relationship with mother," "childhood abuse," and/or "blame for drug use," whereas another coder may have placed this mention within the childhood abuse domain only. Still, intercoder reliability ratings were acceptable (kappa coefficients were generally 0.70 or higher). The tree node domains helped us organize the transcripts into meaningful segments, but ultimately, our conclusions were based on a holistic reading of the interviews in their entirety, looking for trends in those interviews that involved true desistance compared to those that did not [87]. Moreover, this analysis strategy is consistent with the philosophy of qualitative and constructivist/interpretivist research [11] compared to a more quantitative approach.

\section{Self-Reported Desistance}

Interviews revealed that respondents whose official arrest histories may have been consistent with the trends exhibited in the desisting trajectories sometimes reported still being involved in criminal activity and/or engaged in illegal substance use. Previous studies suggest that this is a common phenomenon $[40,95]$. To more accurately capture desistance, we operationalize desistance using self-reported behavior for our qualitative analyses. As most official and self-reported offending data indicate that many offenders intermittently engage in criminal behavior [27, 94], proposing a time cutoff point from which to denote desistance is a fairly precarious enterprise. Besides, many social scientists acknowledge the importance of dynamic influences that allow for a gradual (even intermittent) move from crime and substance abuse [70]. We recognize these issues and have adopted what we believe to be a relatively conservative definition of desistance. Like Maruna [73], who noted that "12 months of drug-free, crime-free, and arrest-free behavior is a significant life change worthy of examination" (p. 48), we operationalized self-reported desistance as not being under correctional supervision and not having engaged in any criminal activity during the past 12 months at the time of the interview. Substance use desistance was defined as not being under correctional supervision and not having used illegal drugs, including misused prescribed medications, or not having consumed alcohol if addicted to alcohol, during the past 12 months at the time of the interview.

Table 1 presents descriptive information on self-reported desistance for the 105 female cases in which self-reported desistance could be validly coded in the transcribed interviews. As can be seen, at the time of their interviews, the majority (54\%) of all respondents reported using illegal substances during the past 12 months, regardless of having no official arrests in the previous year, but fewer were still engaging in other illegal activity (24\%). It should also be noted that there were no race differences in selfreported desistance: $53 \%$ of Black women reported using illegal substances within the past year compared to $57 \%$ of White women; 24 and $25 \%$ of Black and White women, respectively, reported engaging in other criminal activity. The qualitative analysis that follows provides the themes that emerged regarding the effect of age at baseline incarceration release on offending and drug use for those who self-reported having desisted from both substance abuse and crime, as well as those who were still persisting in those activities. 


\section{Results}

\section{Quantitative Data Analyses}

Using these five groups of women with distinct offending trajectories, we estimated a series of multinomial regression models to predict the likelihood that for this all-female sample, women's age at baseline release had an impact on the probability of trajectory group membership. Since we are interested in distinguishing those who desisted from those who persisted, and since the two persisting groups display such distinct official arrest patterns (reflecting perhaps distinct developmental histories), we estimated two sets of multinomial regression models. In the first set, the high-level persisters are the reference group, and in the second, the low-level persisters served as the reference category. Because there were no significant differences across coefficients between the two comparison group models, we present the model using group 4, the "high-level persisters," as the reference group in Table 2. As shown, the only significant factor that affected group membership was "age at release," and this only increased the probability of being in group 2 (medium-level desisters) compared to group 4 (high-level persisters). Women who were older when released at baseline were more likely to be in the medium-level desisting group compared to the high-level persisting group. To explore whether there would be more power in predicting a binary desistance variable, we created a variable coded 1 for those women who belonged to desisting trajectory groups (groups 2, 3, and 5) and 0 for those we belonged to the two persisting groups (groups 1 and 4). Results of the logistic regression model (not shown here) indicate that age at release was the only significant factor that affected the probability of being in the desisting group $(\operatorname{Exp}(B)=1.075, p<0.008)$. For every 1-year increase in age at release, the odds of being in the desisting group compared to the persisters increased by $7.5 \%$. This supports the contention that leaving prison as an older woman increases the likelihood of desistance, particularly for those who may not be entrenched within the criminal justice system.

It is important to note that our decision to highlight the impact of women's "age at baseline release" on the likelihood of desistance membership, as opposed to the impact of "age" as a mere biological measure, is purposeful. First, the correlation between age and age at release is 0.98 , indicating that the two variables are essentially measuring the same thing in the model. As such, there is no way to include both variables in the same model. Secondly, measuring the impact of "age at baseline release" is more consistent with our theoretical rationale that women who are older when they are released from prison may be more likely to calculate the true costs of persisting in offending since they may have lived on the margins of convention for longer than their younger counterparts, once again, as the ITD posits that criminally involved persons are more likely to seek to desist from crime when the feared self becomes more salient. The salience of the feared self is linked to the age at release from prison since the period of time that one would have to change their life around and desist is shorter when the older one is released. The crucial factor with age at release as it relates to desistance, then, is the time period one perceives that he or she has to avoid the feared self and become the possible self. This fear may increase the likelihood that women released at an older age will be more likely to project the failures that they experience now into the future, which serves to initiate an identity change (Table 3 ). 
Table 2 Distribution of female participants for independent and dependent variables, $N=218$

\begin{tabular}{lll}
\hline & Percent (min, max) & $\begin{array}{l}\text { Mean age at baseline } \\
\text { release (SD) }\end{array}$ \\
\hline Group 1: low-level persisters & 24 & $27.5(5.6)$ \\
Group 2: medium-level desisters & 22 & $32.5(5.8)$ \\
Group 3: low-level desisters & 34 & $30.2(6.8)$ \\
Group 4: high-level persisters & 11 & $29.3(4.3)$ \\
Group 5: high-level desisters & 10 & $28.5(6.3)$ \\
Lived with minor children post-release & 63 & \\
Partnered & 13 & \\
Was in prison before baseline & 40 & \\
Had been in drug treatment & 74 & \\
White & 27 & \\
Mean age at baseline release & $29.8(18,51)$ & \\
Mean risk taking score & $2.3(0,7)$ & \\
\hline
\end{tabular}

Of course, quantitative findings that are derived from a truncated sample size are limited in the extent to which they can illuminate the reality and significance of age for this sample of drug-involved women. Also, we recognize that because the baseline incarceration measure does not capture the heterogeneous incarceration history of all of women observed, it is important for us to conceptually explore how age might shape the trends revealed by the quantitative analyses. Criminologists have explored the causal mechanisms for women's desistance, but we have yet to explore how age, experience, and maturity condition those mechanisms for a contemporary druginvolved female sample. To better understand the role of aging and maturity on the perception that the costs of substance abuse and offending over time are higher, the

Table 3 Multinomial regression results (exponentials of regression coefficients) predicting trajectory membership for females using group 4 (high-level persisters) as the comparison category $(N=216)$

\begin{tabular}{lllll}
\hline & G1: LLP & G2: MLD & G3: LLD & G5: HLD \\
\hline Lived with minor children post-release & 1.07 & 0.78 & 0.94 & 0.96 \\
Partnered & 0.95 & 0.55 & 0.44 & 0.81 \\
White & 0.84 & 0.65 & 1.26 & 2.40 \\
Was in prison before baseline & 0.96 & 0.62 & 0.93 & 1.29 \\
Risk taking score & 0.10 & 0.87 & 0.86 & 0.70 \\
In drug treatment at time of release & 1.5 & 1.10 & 2.51 & 0.52 \\
Age at baseline release & 0.94 & $1.09^{*}$ & 1.02 & 0.98 \\
\hline
\end{tabular}

$-2 \mathrm{LL}=591.816$, chi-square $p<0.001$, Nagelkerke $=0.187$

One-tailed significance $* p<0.05$

${ }^{\text {a }}$ A summated scale comprised seven items asking respondent if they would like to dive off high diving boards, try sky diving, learn how to scuba dive, climb steep mountains, try to water ski, do dangerous things, and try new things even if they are scary. In a one-factor model (37\% of the variance), all factor loadings were 0.50 or higher and Cronbach's reliability alpha was 0.73 
next part of our analysis draws upon the interview data collected from 118 women from the original cohort.

\section{Qualitative Data Analyses}

In a prisoner reentry context marked by a swelling geriatric population, it is important to investigate whether age and maturity ready women to benefit from the assumed positive and supervisory elements that informal social bonds and institutions often confer and/or whether age and maturity play any role in women's propensity to achieve cognitive transformations and mobilize their individual agency. The following section explores women's conceptualization of their reentry experiences and the extent to which their age shaped reentry processes and their responses to opportunities and setbacks. In this section, we examined how women in the sample perceived age to affect their substance use disorders and offending patterns after their baseline incarceration release. As the age range for the baseline time of release was 18 to 51 years, with a median value of 45 years, we refer to women as "younger" who were released from their baseline incarceration by the age of 45 years. Women who were released from their baseline sentence at the age of 46 or older were classified as "older."

Having conducted, transcribed, and coded the interviews, we knew that a few women in the less criminally active desisting groups reported that their one and only brief incarceration stint yielded a sufficient "scared straight" response that precluded any future arrests or risky offending behaviors. These few women shared that they were "one and done" and had learned their lessons, never to put their freedom and safety at risk again. Regrettably, most of the women interviewed who made those promises upon their baseline release from prison ultimately broke them. What stood out, however, was the age of the women who made and kept those promises never to return to prison, particularly among those women who had led relatively serious and habitually criminal lives. Narratives revealed that there is something qualitatively different about being released from one's baseline prison sentence later during the life course, rather than earlier. Consistent with the quantitative findings discussed above, these women's narratives also suggest that age and maturity imposed a substantial impact on their readiness to change their identities into prosocial identities as well as their ability to intentionally act to do so. Theories of offending that endeavor to explain women's criminal pathways identify employment, parenting, romantic relationships, and substance abuse as salient life course influences in the offending trajectory model. In this study, we analyzed the narratives drawn from the women in this sample to explore the extent to which their descriptions of desistance include an identification of age as a moderator of these gendered life course events.

\section{Employment}

Occupational niching is a significant restriction that women navigating the contemporary labor market must reconcile $[13,64]$. Socialization and institutional discriminatory practices steer women toward clerical and low-paying roles in education, healthcare, and hospitality [33], and the collateral impact that certain drug-related convictions have on employment eligibility in these sectors disproportionately affects poor, undereducated job-seeking women [3, 18, 120]. For many women leaving prison, securing 
employment in sectors serving vulnerable populations (children, elderly, patients) with a drug felony conviction is nearly impossible. In our sample, those who were able to secure employment credited a fortuitous opportunity, input from a willing and respected reference, or having lied about their criminal background.

Interestingly, despite the magnitude of the stakes stacked against them, many of the women who were younger at the time of their baseline release were more likely to report that they were still using drugs and committing crimes well after they had secured a job upon leaving prison. Younger women like Jacqueline not only confidently expressed that she could work, mother, use, and "hustle" (she participated in a small local cocaine distribution ring) without skipping a beat, but she explained that if she lost her job or was "down for a spell" (briefly incarcerated), she could and did always bounce back economically. Chelsea shared that because she was young at the time and did not present as a woman who was as criminally enmeshed as she in fact was, she never had a problem securing work and, subsequently, never treated the efforts connected to finding or keeping jobs, with any lasting seriousness:

Chelsea: [I was working] as an office manager... I didn't work for them long at all because I ripped them off something terrible. I did payroll so I would always do my own payroll. Wouldn't be what it was supposed to be, or I would do petty cash and use it for me. I had access to all their charge cards, all their checkbooks, like the fool who never did the background check. All their checks I was writing out to pay my bills...

Interviewer: So you hid it from the onset? Why do you think they didn't do a background check or did they know you had a record or things like that?

Chelsea: Well, I hate to tell you this but I can pretty much walk in anywhere and sell myself with a job. My girlfriend told me, "you are the only person I know who can go out one morning and come back with 10 jobs that day." You know when they tell you "sell yourself?" Well, I do.

Chelsea recounted having operated that way for years. Her youthful looks and demeanor never raised any alarms, and because she sought out job opportunities where references were seldom requested and background checks were never run, her past remained her secret. She admits that as a young, relatively good-looking woman, she had yet to mention, let alone confront a feared self that might one day be unemployable, and therefore continued to operate in ways that were consistent with her offender identity. We would also venture that Chelsea is taking advantage of White privilege that keeps her from the gaze of suspicious employers who might prejudge a woman of color and ensure that a background check was conducted or decide not to consider her candidacy at all (for a discussion of persistent employer bias, as well as suspicion and stigmatization of criminal justice involved Black job applicants, see $[23,60,72,126])$.

In contrast, older women who were released from their baseline sentences later in life who often faced both the threat of being labeled as habitual offenders and carried the additional weight of substance abuse-related health complications talked at length about how difficult their job-seeking efforts were and how badly they wanted to succeed in finding and keeping work. Between lamentations over the 
precarious part-time scheduling practices in retail and hospitality sectors [42], decreased mobility, and chronic pain that limited their already bleak work prospects and the realization that there was no longer anyone in their lives to support them, these women communicated a strong need to find and keep any job that would employ them. It is important to note that older women, more than older men, face employment discrimination along aesthetic criteria, too, where occupational niching in service sector roles mandates adherence to standards of beauty that long-term drug-abusing women often fail to meet [24, 81, 82]. The toll that this gendered practice takes on self-esteem for women is immense. Mona is a career waitress who, at the time of her interview, was desperately trying to rehabilitate her foot (injured due to diabetes complications) and find a steady-paying job before her cousin's hospitality grace ran out. She had been living with her cousin for some time but knew that the arrangement was not permanent and that she needed to cement a means to independently support herself. Given the reality of her urgent circumstances, Mona was working hard not only to stay clean, both so she could keep a job and support herself, but also to avoid completely diminishing her cousin's patience and generosity. Despite her dwindling comfort and self-esteem, she was committed to reclaiming the work ethic that she once maintained and is looking for a break from an employer who will give her one more chance to perform as she believes that she one day can. This example is consistent with Aday and Farney's [1] study findings highlighting that older female inmates must reconcile a unique set of healthcare complications that are often poorly addressed while in custody and even ignored upon reentry. Many prison facilities and community correctional settings are ill equipped to meet the needs of ailing women, which may only exacerbate desistance outcomes in the long term.

Although Darcy's story was not common for this sample, it is important to share the illustration that she provides about readiness and taking a major step forward toward accountability and identity change after so many years of doing the opposite. Like Chelsea, Darcy knew precisely what sort of work environment that she could return to and continue to use and break the law. After a series of DUI-related arrests and convictions, she left her baseline incarceration at 43 years old with the understanding that she had to abandon all elements of her life that enabled her addiction-which included a promise not to return to the employer that allowed her to continue to use. Even upon learning that she could come back to her job after 2 weeks of unpaid detox, she still maintained that she had to make a major change to her daily practice if she was going to stay clean:

Darcy: I do not go around any of my old friends. Not whatsoever. I no longer work at [former employer]. I've been gone from there. When I went into my recovery I quit... It wasn't nobody's fault there but I know that place was a big trigger for me because I was well loved there. Well liked and well known and no matter what I did they were going to love me and let me do whatever I wanted to do. I mean I know my boss knew I was high and messing up but he just turned the cheek... That was a huge step... Absolutely.

Interviewer: How did you get to that point? Because I know there had to be a big decision that you... 
Darcy: ... [T] o me it was a blessing in disguise from God. He just shut the doors. Okay, I mean honestly, that's how I feel today when I look back in hindsight and think about everything. So it was like, if I wanted to get clean and sober and stay that way, I had to quit my job so I could do my 10-day outpatient detox there, so that's what I did... So on my tenth day of my detox I was feeling you know, pretty good and I was like you know, I need to find a job... I don't want to go back there... So the rest of that is just history now. It's history. No more alcohol, no drugs, no anything.

In a constricted labor market, it took a great deal of courage for an uneducated, low-skilled job candidate like Darcy to make that decision, but she arrived at a point in her life where she knew that her past practices and thought processes were no longer tenable if she truly aimed to take on a new nonoffender identity and pursue her "possible self." Rather than perpetuate the circumstances that led to the same outcomes, she divorced herself from the employment setting that fostered her addict identity.

\section{Parenting}

Consistent with extant literature on the relationship between motherhood and desistance $[9,10,101]$, many women shared that despite their responsibilities as a primary caregiver, motherhood status did not prompt a desire to desist from crime initially. Some even shared that the stresses of parenthood (particularly if tackled as a single and unsupported mother) actually exacerbated their addiction and offending likelihood. Others very clearly remembered wanting to be mothers to their children but recalled not being ready to battle their addictions and abandon the lives and identities to which they were so attached. Numerous women, representing the range of ages, had one or more pregnancies for which they were inadequately equipped, and their children were surrendered to foster care, adoption, or the guardianship of other relatives. For example, Mary struggled with addiction for most of her youth and early adult life. She allowed her first son to be adopted because she was addicted to heroin at the time of his birth and her parents refused to take custody of him. This caused her a great deal of heartache and guilt, but she saw no other choice at the time as she was not clean and in no position to raise her son. She spent almost two decades battling her addiction, in and out of prison, and living on the street between incarceration bids.

Some of the women who were released from baseline incarcerations later in life shared that a tremendous amount of work had to be done to get clean, stay clean, and redeem their perceived failure at such a significant gender role, like motherhood. For these women, the motherhood role served as the anchor for their new desister identity. Many efforts had to be made to reunite with those children, a significant proportion of whom were teenaged or older and understandably resentful from the experiences that they had suffered. Familial tensions were typical of women who had spent years battling addiction, and as a result, they had to convince not only criminal justice officials that they had finally changed but also their children and other extended family members as well. In fact, Desirée, who desisted in her late 50s and reestablished a relationship with her adult children, recalled them not letting her leave the house alone 
for several months following her last release from prison. She used a grade-school metaphor to describe the accountability measure imposed by her family:

It was like "the buddy system" for little kids. It was like they didn't trust me to do anything by myself because they thought I would go out and get high so they never let me go out alone for a long time.

While many reunion narratives illuminated that the difficult terrain women must navigate when stepping back into a family life as a biological mother, they also included remarks about the need for accountability and the incontestable value of the time investment. Desirée was unwilling to make that commitment earlier in her adult life, but upon leaving prison as an older adult, she knew that that was her last opportunity to "get right" with her family and cement a desister identity. Confronting the impending failed parent feared self as an older woman prompted her to reevaluate her stake in fulfilling her role as a mother.

Grandchildren also provided many of our desisting respondents with a second chance or, as they described it, an opportunity to get parenting "right." Sharon was in and out of prison for much of her adult life, and her mother had custody of her daughter. When she got out of prison and clean in her late 40s; however, Sharon was there to support her daughter when she had her first child and recalled the joy it brought to their family:

I'm there with her [daughter] and I'm helping her raise her kids now. And you know what she told me? You know I'll tell you what she told me because my mother had guardianship of her when I was doing all my mess and right before my birthday, she said, “Mom, you weren't there for me when I was coming up, but I was taken care of . . . but I'm glad you're here now. 'Cause now is when I really need you." Girl, tears just started rolling down . . . and that made me feel some kind of good, you hear me?!

These sorts of second chances at parenting, particularly for women who were older and had spent many years apart from their families, were an extremely important part of reinforcing their new prosocial nonoffender identities as well as helping to heal the pain that resulted from the severed bonds that they had with their own children. As time was perceived to be running out and the feared self became increasingly imminent, older women were more likely to work harder to commit to their parenting and/or grandparenting roles that were consistent with a prosocial self. Although the majority of the women who had desisted were aware of the precarious nature of sobriety, most no longer perceived themselves as addicts or criminals. Tanya stated simply, 'I'm sick of what I had to give up because of this drug. I'm no longer looking at myself as an addict . . . I see myself as a mother, as a daughter, a friend."

\section{Marriage and Romantic Relationships}

The impact that romantic partners played on these women's offending trajectories was quite mixed. There were many women who directly tied their offending and drug abuse patterns to their partners' illegal activity. Those women cited that desisting while in 
those relationships was difficult to do or simply not desired at that time anyway. Others talked about ultimatums that nonoffending partners presented-some of which were successful, others of which could not compete with the pull of addiction. Consistent with existing literature that explores these partnership dynamics, many of these ultimatums centered on the women's failings at managing the "private sphere" of labor and life $[4,56]$. Still, some women talked about partners who supported their in-custody recovery efforts from the outside or even got clean with them, if they had been using, too. Both women who were released earlier in their lives and those who left their baseline incarcerations later in the life course described a number of different relationship types, impacts, successes, and failures.

One distinction that did stand out was that for women who were in caustic relationships or pursued destructive partners, it often took decades of risk, harm, and costs before the pattern of poor choices was apparent. Even then, some women did not move to make changes unless they had imagined for themselves a life and identity that diverged from those patterns and that partner. Deirdre got clean when she stopped prostituting herself to men who offered her drugs, but she was only prompted to do so when the persona she had carried for so long became so clearly inconsistent with the person she and her family knew she could be. When asked what eventually prompted her departure from the bar and lounge scene and the boyfriends who had disappointed her for so many years, she replied:

I'd say... being aware and paying attention to what these people are saying. They're not practicing what they're preaching is what I'm saying. And you're never gonna get well if you keep lying to yourself. You're the main person you gotta stop lying to... My family, they were really disappointed in me, and myself also, because I knew I was better than that.

The repeated discontents coupled with the knowledge that she was headed down a frightening path likely marked by sexually transmitted infection, unplanned pregnancy, and persistent victimization prompted Deidre to reprioritize her desires and her potential. Despite confronting this reality and the crystallization of discontent upon leaving prison in her early 50s, it was still years before she could arrive at that place, however.

Conversely, Donna is a persister who had been in and out of criminal justice supervision and custody since her early teens. She shared that upon leaving prison at the age of 32 years old, she had no intention of curbing her offending behaviors. She contended that everyone close to her, including her long-time partner (referenced below), knew that she was a good person and that her record was not a reflection of who she really was:

You can call him up right now and he'll tell ya! That's all just bad luck and bullshit. He knows I'll always be back and I'll always be his. I wouldn't hurt anybody important and he knows that and so does everybody else.

It appears that neither Donna nor her partner see her offending identity as consistent with who she really is as an individual. Insofar as she is not challenged to confront the impracticality of her continued offending patterns, she did not feel compelled to make any changes to her offending persona and practices. Donna is not at all troubled by her 
imagined future, and her working identity is one that she and her partner are comfortable with and even celebrate, it appears. She did note that after every stint, she returns home to him, that he supports their family while she is in custody, and that he has never once imposed an ultimatum. Perhaps, one explanation for why Donna's future does not appear to incite any anxiety is that she believes that her partner will always support her and her children. With the exception of research conducted by Einat et al. [35], little research exists on the impact that men who remain married or partnered with offending women has on women's desistance, and whether that influence is at all moderated by the partners' ages.

\section{Substance Abuse}

Women interviewed for this study did not identify age as a significant factor in their journeys toward desistance from substance abuse. In fact, many still used well into their adult lives and some were still wrestling with substance use disorders at the time of their interview. Many women described the onset of substance abuse and criminal offending as characteristic of teenage boredom, curiosity, and deviance. Many spoke of precarious times during their childhoods when they worked hard to emulate older siblings or cousins or would willfully do anything to impress an older man despite warnings of his ill intentions. Others described witnessing their parents' parties and simply experimenting with leftover joints and bottles of alcohol. Many also attributed their onset and sustained substance abuse patterns to the desire to escape the weight and suffering attached to traumatic life events. Finally, a number of the women interviewed cited their own immaturity and naivety, and so naturally, the reasons and experiences that sparked youth deviance onset are vast and fairly consistent with the extant literature. The diversity of substance abuse narratives, however, begins to narrow as the women age.

One theme that did emerge from women who left prison later in life, and had either desisted from substance use or had significantly reduced their participation and visibility in the illicit drug market, was comments that captured the drug market's shifting cultural and operational terrain, as well as the array of associated risks that they were no longer willing to take. Women expressed a fear of contracting HIV via intravenous drug administration and unprotected sexual encounters. They also hesitated to buy degraded quality drugs from dealers who they described as ruthless teens who were disrespectful and violent. Some also knew that policing practices had become more vigilant and that they were more likely to get caught in open-air markets and face prison sentences that had become harsher. In addition, the mark of a habitual offender status guaranteeing 25 years in prison is nothing to blink at when approaching your golden years. In light of the realization that their present did not give rise to a future that they wanted to imagine or accept, for some, these risks and strains were enough to prompt women to make moves toward desistance.

Women who were released at baseline when they were older were also more likely to express frustration about the compounding burdens of premature aging, incarceration, friends dying, as well as familial sacrifices and disappointments. Melanie admitted to experiencing diminishing highs and noted the nuisance that buying drugs had become. She spoke at length about how the logistics of scoring and using had weighed such a toll on her psyche and her relationships and how badly she wanted to stop: 
[W] hen you get older the less you enjoy it, the more it became a hassle, and with my daughter and with work it became a hassle... You get your conscience bothering you and you get all these feelings because they're growing up and your mind's so used to one thing but your mind's growing up and you wanna move on. But, really you're so used to doing something that that's what you end up doing. But you wanna move on so bad... It's indescribable about how much you want to move on but you can't.

Melanie's testimony reveals that confronting the feared self precedes the hard work of recovery. The "I'm tired of being sick and tired" refrain was common and prompted many of the older women to rationally reexamine their choices, their prospects, and their agency. Sheila describes how an overdose shocked her into seeking recovery and family-based therapeutic mechanisms that she had not tried before:

I ended up staying at the hospital because my arm was infected and I had OD'ed... So I signed up for [treatment program] which was an outpatient program. And that was the first program I completed with flying colors, never had a dirty urine, never had anything... I'm in counseling for my son, family therapy with my oldest son to try to get him to understand, "I didn't want to leave you..." But my middle son he's just, he's my miracle because I used so much... I was tired and I was scared. And I robbed so many people that I knew eventually I was gonna die... the way I was living was wrong... [W]hen I took it to the next level, the shooting, I couldn't handle it... it was no longer, there was nothing enjoyable. I didn't like to look in the mirror. I was shooting in my neck. I couldn't hit myself I had tracks everywhere. I just didn't like that... And I was tired of ending up at the hospital. And I was tired of my older son saying 'what's wrong with you?' Why are you like that?' and my mom was getting older and at this time she lost my dad, she lost my brother, she was raising my one kid. It was just bad. And I was tired. And I just knew that even if I had to stay at an $\$ 8$ job forever, at least I showed my kids you could change anything. And that became my focus.

Were it not for her having escalated to intravenous needle use that led to an overdose, Sheila may not have ever come to terms with how harmful her substance abuse had become. In her self-appraisal, she saw what her addiction had done to her and her family and knew that she had to seek treatment that would allow her reclaim some semblance of the identity that she once possessed and of which she was once proud.

Sheila's story reveals another important dimension of the feared self. Many of the women interviewed shared that upon realizing that they had isolated themselves from their conventional pasts and the former identity that sought, valued, and protected prosocial networks, they were devastated and wanted better for themselves. This notion of personal isolation from their connection to any prosocial life is a recurrent theme in former offenders' descriptions of their lives. Sheila vividly describes how embedded in her criminal life she had become and how, because of this criminal embeddedness, it was difficult to gain access to legitimate opportunities without at least some indication on her part that she had started to turn her life around and no longer wanted to be the criminal self that eclipsed her former conventional identity and behaviors. 


\section{Conclusion}

Some theorists have argued that the desistance successes enjoyed by older women is derived from the bonds that they have cultivated within prosocial institutions like family and employment [32], or simply a feature of aging and offending fatigue [47], or even the cultivation of emotionally productive coping mechanisms [43, 44]. It is critical to remark, however, that drug-involved, serious offenders, some of whom are marked by a habitual offender status, still do desist from crime, absent the exclusive draw of prosocial bonds or cognitive emotional change that results only as a consequence of involvement in conventional roles. Many women are parenting and working full-time but still using heavily and involved in illegal activities. Instead, it appears that these women who kept their promise to change their identity and then constructed a prosocial lifestyle that supported that persona were prompted to do so only after linking their failures and realizing that their life histories were stemmed from a criminal self with whom they no longer wanted to identify. Social capital acquired from prosocial bonds is certainly important, but the influence that it imposes is not appreciable until individuals construct an identity that can sustainably benefit from and use to contribute to those connections. These patterns are consistent with the contentions of ITD ([91]: 219) that state: "dissatisfaction with one's old identity and the decision to transform one's self is required for any desistance from crime to take place. While resources for desistance may be available, even if they are considerable resources, they will not be utilized in the long term unless someone has first decided that they no longer want to be committed to crime." Further, that impetus for change appears to be strongly linked to an understanding that the undesired fate of dying alone in prison or on the street is a more conceivable reality for women who are released at a later age, than it is for women who leave prison when they are younger.

These findings appear to support ITD in that moves toward desistance are propagated from the understanding of linked failures, discontent, and individual agency. These narratives suggest that women are prompted by a social-psychological model of cessation whereby physical and mental fatigue associated with the recognition of a feared self prompts a desire for change that unfolds within each of the domainsemployment, motherhood, partnerships, and substance abuse-discussed above. It appears that an imagination around a positive possible self, combined with the reason-based shame and fear connected to certain punishments and/or dying alone as an aging habitual offender, prompts a readiness to design new "scripts" [102] and behavioral templates that are consistent with the nonoffender identity.

We believe that the ITD is a viable alternative perspective on desistance from crime. It is founded on an "internalist" model of rational choice wherein preferences and behaviors are shaped by actor's strong reasons [19] or their ultimate concerns [7], which include one's self-identity. This internalist model relies on the very individualistic mental processes that Giordano et al. (and Sampson and Laub) explicitly reject. The relationships among purpose or strong reasons, human agency, and one's identity are nicely captured by the philosopher Hollis [58: 101] who argued that a person "... acts freely, only if he has good reasons for what he does (and no better reasons for doing something else). He has good reasons, only if he acts in his ultimate interests. His ultimate interests derive from what he essentially is" (emphasis added). An important contribution of the ITD, then, is that it hypothesizes that human agency is critically 
involved in the desistance process, as well as individual cognitive processes. Specially, it insists that unlike both the age-graded and cognitive transformation theories, identity change must come first and this transformation is what initiates subsequent changes in preferences, social networks, and behavior. The ITD argues that offenders must first change their self-identity (who they are and want to be) before prosocial opportunities (like employment and healthy romantic partnerships) arrive and can successfully be taken advantage of or sustained.

We acknowledge that this study is not without its limitations. The quantitative analyses are derived from official arrest records which may not capture the full extent of this sample's offending activity. We also recognize that despite the richness that qualitative data offer the research community, there is always some degree of measurement error. The demonstration of desirability bias among respondents asked to disclose their engagement in deviant and illegal behavior is expected. Still, we believe that this work makes a contribution to the discourse examining identity change and desistance for women, particularly surrounding the needs of older women leaving prison that are compounded by age-related concerns and complications.

As policymakers are eager to find ways to not (just) punish but also help formerly incarcerated women exit criminal activity, we offer a theory of women's desistance that can point toward key, useful features for improved correctional programming. As ITD predicts that exclusive resource devotion to employment and/or substance abuse programming will be largely wasted on individuals who have not yet reached the point where they have decided to adopt a new identity, the idea of cognitively preparing female offenders to make good use of conventional opportunities is an integral component of successful rehabilitation programming [5, 57, 59, 117]. Despite some of the positive developments shared by women who were released from the baseline incarceration at an older age, we are not advocating for longer prison sentences for drug-involved women. Rather, policies informed by ITD might instead require more proactive action on the part of individuals prior to providing employment and/or treatment. This selection would avoid wasting resources with people who are not yet ready to desist (and will not benefit from employment) and avoid creating perverse incentives for those who are still actively involved in crime. Until women's risks are properly defined and assessed, the development of programming that best suits their needs will continue to fall short [53, 54, 84, 114, 129]. Most importantly, we must infuse all programming with an intersectional orientation that accounts for the many victimization, offending, and reentry contexts that women of different races, classes, sexual orientations, and other social loci must navigate [37, 41, 89, 96].

In addition, moving forward, it might be useful for practitioners to consider drafting gender-responsive programming for mothering, vocational training, and substance abuse treatment, in concert with recognition of how those processes and treatment outcomes are related to maturity and agency [38]. Separating older and younger female program participants may also accelerate the development of maturity and the cultivation of agency among female samples who need only realize that they have "outgrown" their past criminal selves and can instead dare to imagine a positive nonoffender identity. Because self-efficacy in criminal offending is tethered to the belief that you can commit and get away with a crime, which is derived from personal and vicarious experiences [67], it could prove helpful to design reentry programming that was somewhat age specific so 
that women leaving prison later in life would not be mixed with those who still believe themselves infallible.

Although this study did not include a comparative gender analysis, existing research suggests that involvement in crime seems to cost women more than their male counterparts [36]. Since we know that rates of female imprisonment are growing, we can predict that the family-level and community-level fallout connected to this trend makes reintegration that much more important. Finally, this mixed-method study also provides an important contribution by offering qualitative analyses that are useful for understanding processes that have long been the domain of quantitative orientation [127] and by shedding light on a relatively understudied sample. We are confident that these findings can inform the research and practitioner community about the developmental process of gendered desistance.

Acknowledgments This project was supported by Grant No. 2008-IJ-CX-0017 awarded by the National Institute of Justice, Office of Justice Programs, US Department of Justice. The points of view presented here are our own and do not necessarily represent the official position or policies of the US Department of Justice.

The development of this manuscript was also supported by a Vice Provost's Postdoctoral Fellowship awarded to the first author while a member of the Department of Criminology at the University of Pennsylvania.

\section{References}

1. Aday, R., \& Farney, L. (2014). Malign neglect: assessing older women's health care experiences in prison. Journal of Bioethical Inquiry, 11(3), 359-372.

2. Agnew, R. (2006). Storylines as a neglected cause of crime. Journal of Research in Crime and Delinquency, 43(2), 119-147.

3. Allard, P. (2002). Life sentences: denying welfare benefits to women convicted of drug offenses. Washington, DC.

4. Anderson, T. L., \& Bondi, L. (1998). Exiting the drug-addict role: variations by race and gender. Symbolic Interaction, 21(2), 155-174.

5. Andrews, D. A., Bonta, J., \& Wormith, J. S. (2011). The risk-need-responsivity (RNR) model: does adding the good lives model contribute to effective crime prevention? Criminal Justice and Behavior, 38(7), 735-755.

6. Apel, R. (2013). Sanctions, perceptions, and crime: implications for criminal deterrence. Journal of Quantitative Criminology, 29(1), 67-101.

7. Archer, M. S. (2000). Being human: the problem of agency. Cambridge: Cambridge University Press.

8. Bachman, R., Kerrison, E., O'Connell, D., \& Paternoster, R. (2013). Roads diverge: Long-term patterns of relapse, recidivism and desistance for a cohort of drug-involved offenders (Grant Number 2008-IJCX-1107). Washington, DC: National Institute of Justice, United States Department of Justice.

9. Bachman, R., Kerrison, E. M., Paternoster, R., Smith, L., \& O'Connell, D. (2016). The complex relationship between motherhood and desistance. Women and Criminal Justice, 26(3), 212-231.

10. Bachman, R., Kerrison, E., Paternoster, R., O’Connell, D., \& Smith, L. (2016). Desistance for a longterm drug involved sample of adult offenders: the importance of identity transformation. Criminal Justice and Behavior, 43(2), 164-186.

11. Bachman, R., \& Schutt, R. (2015). The practice of research in criminology and criminal justice (5th ed.). Thousand Oaks, CA: Sage Publishers.

12. Barnes, S. L., \& Stringer, E. C. (2013). Is motherhood important? Imprisoned women's maternal experiences before and during confinement and their postrelease expectations. Feminist Criminology, 9(1), 3-23.

13. Beechey, V. (2013). Women and production: a critical analysis of some sociological theories of women's work. In A. Kuhn \& A. Wolpe (Eds.), Feminism and materialism: women and modes of production (pp. 155-197). New York: Routledge. 
14. Belknap, J. (2010). "Offending women”: a double entendre. Journal of Criminal Law and Criminology, 100(3), 1061-1097.

15. Belknap, J. (2015). The invisible woman: gender, crime, and justice (fourth). Stamford: Cengage Learning.

16. Belli, R. F., Stafford, F. P., \& Alwin, D. F. (2009). The application of calendar and time diary methods in the collection of life course data. In R. F. Belli, F. P. Stafford, \& D. F. Alwin (Eds.), Calendar and time diary: methods in life course research (pp. 1-4). Thousand Oaks: Sage Publishers.

17. Bersani, B. E., Laub, J. H., \& Nieuwbeerta, P. (2009). Marriage and desistance from crime in the Netherlands: do gender and socio-historical context matter? Journal of Quantitative Criminology, 25(1), $3-24$.

18. Bloom, B., Owen, B., \& Covington, S. (2004). Women offenders and the gendered effects of public policy. Review of Policy Research, 21(1), 31-47.

19. Boudon, R. (2003). Beyond rational choice theory. Annual Review of Sociology, 29, 1-21.

20. Breen, A. V. (2014). Changing behavior and changing personal identity: the case of pregnant and parenting young women and antisocial behavior. Identity, 14(1), 60-79.

21. Brown, M., \& Ross, S. (2010). Mentoring, social capital and desistance: a study of women released from prison. Australian and New Zealand Journal of Criminology, 43(1), 31-50.

22. Bui, H. N., \& Morash, M. (2010). The impact of network relationships, prison experiences, and internal transformation on women's success after prison release. Journal of Offender Rehabilitation, 49(1), 1-22.

23. Bumiller, K. (2015). Bad jobs and good workers: the hiring of ex-prisoners in a segmented economy. Theoretical Criminology, 19(3), 336-354.

24. Busen, N. H. (2014). An interprofessional education project to address the health care needs of women transitioning from prison to community reentry. Journal of Professional Nursing, 30(4), 357-366.

25. Bushway, S. D., \& Paternoster, R. (2011). Understanding desistance: theory testing with formal empirical models. In J. MacDonald (Ed.), Measuring crime and criminality: advances in criminological theory (Vol. 17, pp. 299-333). New Brunswick: Transaction Publishers.

26. Bushway, S. D., \& Paternoster, R. (2013). Desistance from crime: a review and ideas for moving forward. In C. L. Gibson \& M. D. Krohn (Eds.), Handbook of life-course criminology (pp. 213-231). New York: Springer.

27. Carlsson, C. (2013). Processes of intermittency in criminal careers: notes from a Swedish study on life courses and crime. International Journal of Offender Therapy and Comparative Criminology, 57(8), 913-938.

28. Cauffman, E., Monahan, K. C., \& Thomas, A. G. (2015). Pathways to persistence: female offending from 14 to 25. Journal of Developmental and Life-Course Criminology, 1(3), 236-268.

29. Chesney-Lind, M., \& Pasko, L. (Eds.). (2013). The female offender: girls, women, and crime (3rd ed.). Thousand Oaks: Sage Publications.

30. Cobbina, J. E. (2010). Reintegration success and failure: factors impacting reintegration among incarcerated and formerly incarcerated women. Journal of Offender Rehabilitation, 49(3), 210-232.

31. Corbin, J., \& Strauss, A. (2015). Basics of qualitative research (fourth). Thousand Oaks, CA: Sage Publications.

32. Craig, J., \& Foster, H. (2013). Desistance in the transition to adulthood: the roles of marriage, military, and gender. Deviant Behavior, 34(3), 208-223.

33. Damaske, S. (2011). A "major career woman"?: how women develop early expectations about work. Gender and Society, 25(4), 409-430.

34. De Li, S., \& MacKenzie, D. L. (2003). The gendered effects of adult social bonds on the criminal activities of probationers. Criminal Justice Review, 28(2), 278-298.

35. Einat, T., Harel-Aviram, I., \& Rabinovitz, S. (2015). Barred from each other: why normative husbands remain married to incarcerated wives - an exploratory study. International Journal of Offender Therapy and Comparative Criminology, 59(6), 654-679.

36. Estrada, F., \& Nilsson, A. (2012). Does it cost more to be a female offender? A life-course study of childhood circumstances, crime, drug abuse, and living conditions. Feminist Criminology, 7(3), 196-219.

37. Fader, J. J., \& Traylor, L. L. (2015). Dealing with difference in desistance theory: the promise of intersectionality for new avenues of inquiry. Sociology Compass, 9(4), 247-260.

38. Farrall, S., \& Maruna, S. (2004). Desistance-focused criminal justice policy research. The Howard Journal of Criminal Justice, 43(4), 358-367.

39. Farrington, D. P. (1986). Age and crime. Crime and Justice, 7, 189-250.

40. Farrington, D. P., Ttofi, M. M., Crago, R. V., \& Coid, J. W. (2014). Prevalence, frequency, onset, desistance and criminal career duration in self-reports compared with official records. Criminal Behaviour and Mental Health, 24(4), 241-253. 
41. Foster, H., \& Hagan, J. (2015). Punishment regimes and the multilevel effects of parental incarceration: intergenerational, intersectional, and interinstitutional models of social inequality and systemic exclusion. Annual Review of Sociology, 41, 135-158.

42. Frank-Miller, E. G., Lambert, S. J., \& Henly, J. R. (2015). Age, wage, and job placement: older women's experiences entering the retail sector. Journal of Women \& Aging, 27(2), 157-173.

43. Giordano, P. C., Cernkovich, S. A., \& Rudolph, J. L. (2002). Gender, crime, and desistance: toward a theory of cognitive transformation. American Journal of Sociology, 107(4), 990-1064.

44. Giordano, P. C., Schroeder, R. D., \& Cernkovich, S. A. (2007). Emotions and crime over the life course: a neo-meadian perspective on criminal continuity and change. American Journal of Sociology, 112(6), 1603-1661.

45. Giordano, P. C., Seffrin, P. M., Manning, W. D., \& Longmore, M. A. (2011). Parenthood and crime: the role of wantedness, relationships with partners, and ses. Journal of Criminal Justice, 39(5), 405-416.

46. Glaze, L. E., \& Maruschak, L. M. (2008). Parents in prison and their minor children. Washington, D.C.: Bureau of Justice Statistics.

47. Gottfredson, M. R., \& Hirschi, T. (1990). A general theory of crime. Stanford: Stanford University Press.

48. Greenfeld, L. A., \& Snell, T. L. (1999). Women offenders. Washington, DC: Bureau of Justice Statistics, U.S. Department of Justice.

49. Griffin, M. L., \& Armstrong, G. S. (2003). The effect of local life circumstances on female probationers' offending. Justice Quarterly, 20(2), 213-239.

50. Gueta, K., \& Chen, G. (2016). "I wanted to rebel, but there they hit me even harder": discourse analysis of Israeli women offenders' accounts of their pathways to substance abuse and crime. International Journal of Offender Therapy and Comparative Criminology, 60(7), 787-807.

51. Gunnison, E. (2014). Desistance from criminal offending: exploring gender similarities and differences. Criminology, Criminal Justice, Law and Society, 15(3), 75-95.

52. Gunnison, E., \& McCartan, L. M. (2005). The role of different developmental experiences: a theoretical examination of female persistence. Women and Criminal Justice, 16(3), 43-65.

53. Guthrie, B. (2011). Toward a gender-responsive restorative correctional health care model. Journal of Obstetric, Gynecologic, and Neonatal Nursing, 40(4), 497-505.

54. Hannah-Moffat, K. (2005). Criminogenic needs and the transformative risk subject: hybridizations of risk/need in penality. Punishment and Society, 7(1), 29-51.

55. Harding, D. J., Wyse, J. B., Dobson, C., \& Morenoff, J. D. (2014). Making ends meet after prison. Journal of Policy Analysis and Management, 33(2), 440-470.

56. Harris, A. (2011). Constructing clean dreams: accounts, future selves, and social and structural support as desistance work. Symbolic Interaction, 34(1), 63-85.

57. Heidemann, G., Cederbaum, J. A., \& Martinez, S. (2015). Beyond recidivism: how formerly incarcerated women define success. Affilia, 1-17.

58. Hollis, M. (1977). Models of man: philosophical thoughts on social action. Cambridge, UK: Cambridge University Press.

59. Hlavka, H., Wheelock, D., \& Jones, R. (2015). Exoffender accounts of successful reentry from prison. Journal of Offender Rehabilitation, 54(6), 406-428.

60. Holzer, H. J., Raphael, S., \& Stoll, M. A. (2006). Perceived criminality, criminal background checks and the racial hiring practices of employers. Journal of Law and Economics, 49(2), 451-480.

61. Huebner, B. M., DeJong, C., \& Cobbina, J. (2010). Women coming home: long-term patterns of recidivism. Justice Quarterly, 27(2), 225-254.

62. Inciardi, J. A., Martin, S. S., \& Butzin, C. A. (2004). Five-year outcomes of therapeutic community treatment of drug-involved offenders after release from prison. Crime and Delinquency, 50(1), 88-107.

63. James, D. J., \& Glaze, L. E. (2005). Mental health problems of prison and jail inmates. Washington, DC: Bureau of Justice Statistics, U.S. Department of Justice.

64. Kabeer, N. (2016). Gender equality, economic growth, and women's agency: the "endless variety" and "monotonous similarity" of patriarchal constraints. Feminist Economics, 22(1), 295-321.

65. King, R. D., Massoglia, M., \& Macmillan, R. (2007). The context of marriage and crime: gender, the propensity to marry, and offending in early adulthood. Criminology, 45(1), 33-65.

66. Kreager, D. A., Matsueda, R. L., \& Erosheva, E. A. (2010). Motherhood and criminal desistance in disadvantaged neighborhoods. Criminology, 48(1), 221-258.

67. Laferriere, D., \& Morselli, C. (2015). Criminal achievement and self-efficacy. Journal of Research in Crime and Delinquency, 52(6), 856-889.

68. Laub, J. H., Nagin, D. S., \& Sampson, R. J. (1998). Trajectories of change in criminal offending: good marriages and the desistance process. American Sociological Review, 63(2), 225-238. 
69. Laub, J. H., \& Sampson, R. J. (2003). Shared beginnings, divergent lives: delinquent boys to age 70. Cambridge: Harvard University Press.

70. LeBel, T. P., Burnett, R., Maruna, S., \& Bushway, S. (2008). The "chicken and egg" of subjective social factors in desistance from crime. European Journal of Criminology, 5(2), 131-159.

71. Leverentz, A. M. (2006). The love of a good man? Romantic relationships as a source of support or hindrance for female ex-offenders. Journal of Research in Crime and Delinquency, 43(4), 459-488.

72. Lutman, B., Lynch, C., \& Monk-Turner, E. (2014). De-demonizing the "monstrous" drug addict: a qualitative look at social reintegration through rehabilitation and employment. Critical Criminology, 23(1), 57-72.

73. Maruna, S. (2001). Making good: how ex-convicts reform and rebuild their lives. Washington, DC: American Psychological Association.

74. Maruna, S., Lebel, T. P., Mitchell, N., \& Naples, M. (2004). Pygmalion in the reintegration process: desistance from crime through the looking glass. Psychology, Crime \& Law, 10(3), 271-281.

75. Maruna, S., \& Roy, K. (2007). Amputation or reconstruction? Notes on the concept of “knifing off' and desistance from crime. Journal of Contemporary Criminal Justice, 23(1), 104-124.

76. Mazerolle, P., Brame, R., Paternoster, R., Piquero, A., \& Dean, C. (2000). Onset age, persistence, and offending versatility: comparisons across gender. Criminology, 38(4), 1143-1172.

77. McKay, T., Comfort, M., Lindquist, C., \& Bir, A. (2016). If family matters: supporting family relationships during incarceration and reentry. Criminology and Public Policy, 15(2), 529-542.

78. Michalsen, V. (2011). Mothering as a life course transition: do women go straight for their children? Journal of Offender Rehabilitation, 50(6), 349-366.

79. Michalsen, V. (2013). A cell of one's own? Incarceration and other turning points in women's journeys to desistance. International Journal of Offender Therapy and Comparative Criminology. doi:10.1177/0306624x13498211.

80. Moffitt, T. E., Caspi, A., Harrington, H., \& Milne, B. J. (2002). Males on the life-course-persistent and adolescence-limited antisocial pathways: follow-up at age 26 years. Development and Psychopathology, 14(1), 179-207.

81. Moran, D. (2014). Leaving behind the "total institution"? Teeth, transcarceral spaces and (re)inscription of the formerly incarcerated body. Gender, Place and Culture, 21(1), 35-51.

82. Moran, D. (2012). Prisoner reintegration and the stigma of prison time inscribed on the body. Punishment and Society, 14(5), 564-583.

83. Morash, M., Kashy, D. A., Bohmert, M. N., Cobbina, J. E., \& Smith, S. W. (2015). Women at the nexus of correctional and social policies: implications for recidivism risk. British Journal of Criminology. doi:10.1093/bjc/azv124.

84. Mulla, S., \& Hlavka, H. (2011). Gendered violence and the ethics of social science research. Violence Against Women, 17(12), 1509-1520.

85. Mulvey, E. P., Steinberg, L., Fagan, J., Cauffman, E., Piquero, A. R., Chassin, L., Knight, G. P., Brame, R., Schubert, C. A., Hecker, T., \& Losoya, S. H. (2004). Theory and research on desistance from antisocial activity among serious adolescent offenders. Youth Violence and Juvenile Justice, 2(3), 213-236.

86. Nagin, D. S. (2005). Group-based modeling of development. Cambridge: Harvard University Press.

87. Namey, E., Guest, G., Thairu, L., \& Johnson, L. (2008). Data reduction techniques for large qualitative data sets. In G. Guest \& K. M. MacQueen (Eds.), Handbook for team-based qualitative research (pp. 137-161). Lanham: Altamira Press.

88. National Center on Addiction and Substance Abuse. (2010). Behind bars II: substance abuse and America's prison population. New York: Columbia University.

89. Nyamathi, A. M., Srivastava, N., Salem, B. E., Wall, S., Kwon, J., Ekstrand, M., Hall, E., Turner, S. F., \& Faucette, M. (2016). Female ex-offender perspectives on drug initiation, relapse, and desire to remain drug free. Journal of Forensic Nursing, 12(2), 80-89.

90. Opsal, T. (2012). "Livin" on the straights': identity, desistance, and work among women post-incarceration. Sociological Inquiry, 82(3), 378-403.

91. Paternoster, R., Bachman, R., Bushway, S., Kerrison, E., \& O’Connell, D. (2015). Human agency and explanations of criminal desistance: arguments for a rational choice theory. Journal of Developmental and Life Course Criminology, 1(3), 209-235.

92. Paternoster, R., Bachman, R., Kerrison, E., O’Connell, D., \& Smith, L. (2016). Desistance from crime and identity: an empirical test with survival time. Criminal Justice and Behavior. doi: $10.1177 / 0093854816651905$.

93. Paternoster, R., \& Bushway, S. (2009). Desistance and the "feared self": toward an identity theory of criminal desistance. The Journal of Criminal Law and Criminology, 99(4), 1103-1156. 
94. Piquero, A. R. (2004). Somewhere between persistence and desistance: the intermittency of criminal careers. In S. Maruna \& R. Immarigeon (Eds.), After crime and punishment: pathways to offender reintegration (pp. 101-120). Portland: Willan Publishing.

95. Piquero, A. R., Schubert, C. A., \& Brame, R. (2014). Comparing official and self-report records of offending across gender and race/ethnicity in a longitudinal study of serious youthful offenders. Journal of Research in Crime and Delinquency, 51(4), 526-556.

96. Potter, H. (2015). Intersectionality and criminology: disrupting and revolutionizing studies of crime. New York: Routledge.

97. Richie, B. (1996). Compelled to crime: the gender entrapment of battered black women. New York: Routledge.

98. Richie, B. (2001). Challenges incarcerated women face as they return to their communities: findings from life history interviews. Crime and Delinquency, 47(3), 368-389.

99. Richmond, K. M. (2014). The impact of federal prison industries employment on the recidivism outcomes of female inmates. Justice Quarterly, 31(4), 719-745.

100. Rodermond, E., Kruttschnitt, C., Slotboom, A., \& Bijleveld, C. C. J. H. (2016). Female desistance: a review of the literature. European Journal of Criminology, 13(1), 3-28.

101. Robbins, C. A., Martin, S. S., \& Surratt, H. L. (2009). Substance abuse treatment, anticipated maternal roles, and reentry success of drug-involved women prisoners. Crime and Delinquency, 55(3), 388-411.

102. Rumgay, J. (2004). Scripts for safer survival: pathways out of female crime. The Howard Journal of Criminal Justice, 43(4), 405-419.

103. Sampson, R. J., \& Laub, J. H. (1990). Crime and deviance over the life course: the salience of adult social bonds. American Sociological Review, 55(5), 609-627.

104. Sampson, R. J., \& Laub, J. H. (1993). Crime in the making: Pathways and turning points through life. Cambridge, MA: Harvard University Press.

105. Sampson, R. J., \& Laub, J. H. (1996). Socioeconomic achievement in the life course of disadvantaged men: military service as a turning point, circa 1940-1965. American Sociological Review, 61(3), 347-367.

106. Sanders, C. B., \& Cuneo, C. J. (2010). Social reliability in qualitative team research. Sociology, 44(2), 325-343.

107. Schubert, C. A., Mulvey, E. P., Steinberg, L., Cauffman, E., Losoya, S. H., Hecker, T., Chassin, L., \& Knight, G. P. (2004). Operational lessons from the pathways to desistance project. Youth Violence and Juvenile Justice, 2(3), 237-255.

108. Scott, C. K., Grella, C. E., Dennis, M. L., \& Funk, R. R. (2014). Predictors of recidivism over 3 years among substance-using women released from jail. Criminal Justice and Behavior, 41(11), 1257-1289.

109. Sharpe, G. (2015). Precarious identities: "young" motherhood, desistance and stigma. Criminology and Criminal Justice, 15(4), 407-422.

110. Shover, N., \& Thompson, C. Y. (1992). Age, differential expectations, and crime desistance. Criminology, 30(1), 89-104.

111. Sommers, I., Baskin, D. R., \& Fagan, J. (1994). Getting out of the life: crime desistance by female street offenders. Deviant Behavior, 15(2), 125-149.

112. Taylor, C. J. (2015). Gendered pathways to recidivism: differential effects of family support by gender. Women and Criminal Justice, 25(3), 169-183.

113. Thornberry, T. P., Krohn, M. D., Augustyn, M. B., Buchanan, M., \& Greenman, S. J. (2015). The impact of adolescent risk behavior on partner relationships. Advances in Life Course Research. doi:10.1016/j.alcr.2015.04.002.

114. Tripodi, S. J., \& Pettus-Davis, C. (2013). Histories of childhood victimization and subsequent mental health problems, substance use, and sexual victimization for a sample of incarcerated women in the US. International Journal of Law and Psychiatry, 36(1), 30-40.

115. Turanovic, J. J., Rodriguez, N., \& Pratt, T. C. (2012). The collateral consequences of incarceration revisited: a qualitative analysis of the effects on caregivers of children of incarcerated parents. Criminology, 50(4), 913-959.

116. Uggen, C. (2000). Work as a turning point in the life course of criminals: a duration model of age, employment, and recidivism. American Sociological Review, 65(4), 529-546.

117. Van Voorhis, P., Wright, E. M., Salisbury, E., \& Bauman, A. (2010). Women's risk factors and their contributions to existing risk/needs assessment: the current status of a gender-responsive supplement. Criminal Justice and Behavior, 37(3), 261-288.

118. Varriale, J. A. (2008). Female gang members and desistance: pregnancy as a possible exit strategy? Journal of Gang Research, 15(4), 35-62. 
119. Verbruggen, J., Blokland, A. A. J., \& van der Geest, V. R. (2012). Effects of employment and unemployment on serious offending in a high-risk sample of men and women from ages 18 to 32 in the Netherlands. British Journal of Criminology, 52(5), 845-869.

120. Wahler, E. A. (2015). Retribution or rehabilitation? Conflicting goals of US policies pertaining to drug felonies and their impact on women. Journal of Women, Politics and Policy, 36(1), 95-106.

121. Wakefield, S., \& Wildeman, C. (2013). Children of the prison boom: mass incarceration and the future of American inequality. New York: Oxford University Press.

122. Wattanaporn, K. A., \& Holtfreter, K. (2014). The impact of feminist pathways research on genderresponsive policy and practice. Feminist Criminology, 9(3), 191-207.

123. White, H. R., Buckman, J., Pardini, D., \& Loeber, R. (2015). The association of alcohol and drug use with persistence of violent offending in young adulthood. Journal of Developmental and Life Course Criminology, 1(3), 289-303.

124. White, H. R., Lee, C., Mun, E.-Y., \& Loeber, R. (2012). Developmental patterns of alcohol use in relation to the persistence and desistance of serious violent offending among African American and Caucasian young men. Criminology, 50(2), 391-426.

125. Wolf Harlow, C. (1999). Special report: profile of jail inmates, 1996. Washington, D.C.

126. Wozniak, A. (2015). Discrimination and the effects of drug testing on black employment. The Review of Economics and Statistics, 97(3), 548-566.

127. Wright, K. A., \& Bouffard, L. A. (2016). Capturing crime: the qualitative analysis of individual cases for advancing criminological knowledge. International Journal of Offender Therapy and Comparative Criminology, 60(2), 123-145.

128. Wright, E. M., Van Voorhis, P., Bauman, A., \& Salisbury, E. (2008). Gender-responsive risk/needs assessment: final report. Cincinnati: Criminal Justice Research Center, University of Cincinnati.

129. Wright, E. M., Van Voorhis, P., Salisbury, E. J., \& Bauman, A. (2012). Gender-responsive lessons learned and policy implications for women in prison: a review. Criminal Justice and Behavior, 39(12), $1612-1632$.

130. Wyse, J. J. B., Harding, D. J., \& Morenoff, J. D. (2014). Romantic relationships and criminal desistance: pathways and processes. Sociological Forum, 29(2), 365-385. 